\title{
TRABALHO: NOVOS E VELHOS CONTEXTOS
}

\section{INTRODUÇÃO}

\author{
Iracema B. Guimarães*
}

Os temas relacionados ao mundo do trabalho, expressão aqui utilizada no sentido de universo do trabalho, merecem, mais uma vez, ser contemplados neste espaço de divulgação da produção científica e técnica, ao tempo em que seus impasses e dilemas se encontram no centro das preocupações e manifestações de diferentes segmentos da sociedade brasileira. Em decorrência das transformações que vêm sendo introduzidas em uma configuração já bastante instável, reforça-se o argumento de que o mercado de trabalho no Brasil "nunca foi muito estruturado, uma vez que o desenvolvimento da economia, mesmo recebendo amplo apoio estatal, não foi acompanhado de esforço análogo do poder público para estruturar melhor a compra e venda, o uso e a remuneração da força de trabalho" (Baltar, 2010). Desse modo, mesmo se considerando os ganhos alcançados, torna-se importante dar continuidade aos debates direcionados para as mudanças

* Universidade Federal da Bahia. Faculdade Filosofia e Ciências Humanas. Departamento de Sociologia. Programa de Pós-Graduação em Ciências Sociais. Centro de Estudos e Pesquisas em Humanidade -CRH

Estrada de São Lázaro, 19. Cep. 40.210-730. Federação Salvador - Bahia - Brasil. iracema.brandao60@gmail.com relativas à ocupação da população em idade ativa, diante dos rígidos ajustes gerados pela reestruturação produtiva em curso no Brasil há mais de três décadas, ${ }^{1}$ período no qual o nível de ocupação oscilou, manteve-se relativamente estável e voltou a declinar recentemente, passando de 57,1\% (2012), para 56,9\% (2013) e, finalmente, 54,7 (primeiro trimestre de 2016) e 53,1 (no mesmo período em 2017). ${ }^{2}$ Desde períodos anteriores de franca instabilidade, uma parte desse amplo conjunto de pessoas ocupadas vem sendo obrigada a desenvolver estratégias, ou a recorrer a conhecidas soluções que continuam acionadas nos ciclos de expansão do capital e priorizam: flexibilização no uso da força de trabalho, restrições de acesso aos postos estáveis e interrupções em um processo que caminhava a passos lentos, contribuindo para um aprofundamento

${ }^{1}$ De um modo geral, admite-se que o primeiro país a incorporar com sucesso as mudancas atribuídas à reestruturação produtiva, a partir da década de 1970, foi o Japão, através de um modelo que ficou conhecido como toyotismo. No Brasil e na maioria dos demais países, esse sistema consolidou-se a partir da década de 1980.

${ }^{2}$ Refere-se ao total das pessoas trabalhando, entre aquelas em idade de trabalhar, calculadas segundo as estimativas apoiadas na Pesquisa Nacional de Amostra Domiciliar, Pnad Contínua - IBGE. 
das desigualdades entre o segmento estável e os demais segmentos do mercado de trabalho.

Praticamente, quase nada autoriza a se falar em novos tempos, mas sim na importância de se buscarem melhores conhecimentos sobre a realidade atual, apontando-se as ausências e perdas na relação entre Estado, economia e sociedade, como vem sendo mostrado nos inúmeros estudos existentes sobre o mundo do trabalho, mesmo quando interpretados sob diferentes conotações.

Desse modo, o relativo aumento do funcionamento internacionalizado de determinados setores produtivos, financeiros e de serviços pode ser visto sob ângulos diferentes mas, de fato, coexiste com os outros (nem sempre novos) espaços de reorganização do trabalho que não são separáveis dos complexos processos presentes nos primeiros - conduzindo a deslocamentos dos trabalhadores em busca de trabalho, ao enfrentamento do desemprego, ao rebaixamento de condições laborais e de direitos, e à contratação flexível, em decorrência de uma adesão geral aos modelos de empresa ou instituição flexível, enxuta, e fluida (Bihr, 1998), ainda que dissociados de uma política de empregos.

Reunindo diferentes contextos desse complexo cenário, apresentamos aqui um conjunto de artigos que sinalizam para alguns desses aspectos tanto gerais como mais espe亏ิ cíficos, do funcionamento de um mercado de trabalho cujo relativo declínio no seu nível de ocupação não encobre uma significativa vitali- mundialização do capital, no qual o processo de privatização das empresas estatais foi acelerado. No primeiro artigo aqui apresentado, Nas asas do capital: Embraer, financeirização e implicações sobre os trabalhadores, de autoria de Lívia de Cássia Godói Moraes, focaliza-se o caso da Empresa Brasileira de Aeronáutica S/A (EMBRAER), demonstrando como, no período de sua privatização, houve uma transformação em seus objetivos, associados à dominação do capital financeiro, com progressivos ciclos de reestruturação e ondas de demissões de trabalhadores, cuja análise permite oferecer uma interessante discussão sobre os "voos" do capital na forma de capital financeiro e fictício.

$\mathrm{O}$ artigo seguinte, A face qualificada-especializada do trabalho imigrante no Brasil: temporalidade e flexibilidade, de autoria de Patrícia Villen, focaliza o atual regime de contratação internacional de força de trabalho dentro do circuito legalizado de migração, considerando que ele se insere em uma discussão sobre um "mercado global dos recursos humanos qualificados”, que ganha expressão através da intensificação da mobilidade internacional da força trabalho com perfil qualificado-especializado, compreendida como parte da relação de assalariamento e do atual grau de internacionalização dos processos produtivos e financeiros. Através de um regime legal da imigração e de aberturas a barreiras seletivas, a autora aponta os estudos que investigam os fatores de precarização envolvidos nessa organização internacionalmente móvel de força de trabalho, para focalizar duas categorias singulares: a que se denomina como "os marítimos globais", e aquela mais reconhecida como "os médicos cubanos".

O artigo O trabalho na confecção em São Paulo: as novas formas da precariedade, de autoria de Márcia de Paula Leite, Sandra Roberta Alves Silva, e Pilar Carvalho Guimarães, nos apresenta a outra face do trabalho imigrante, estabelecendo, também, a relação entre a imigração internacional e a intensificação dos fluxos de capital, que, por sua vez, se inserem 
em uma hierarquia urbana internacional situada no contexto da globalização e das crises econômicas e políticas. O trabalho demonstra como elas contribuem para impulsionar fluxos migratórios de massa nos países que perderam o jogo do desenvolvimento, como o caso dos migrantes bolivianos, que atuam no setor de confecções, em São Paulo, através de processos de terceirização e muitas vezes de maneira informal e ilegal.

Já no artigo seguinte, Fábricas recuperadas pelos trabalhadores: os dilemas da gestão coletiva do trabalho, de autoria de Jacob Carlos Lima, e Aline Suelen Pires, analisam-se os casos reconhecidos de fábricas recuperadas, entendendo que, mesmo não tendo uma participação significativa no conjunto da economia do país, assim como no conjunto dos empreendimentos da economia solidária, elas apresentam a singularidade de preservar uma significativa importância simbólica, na medida em que tais empresas são frutos de resistência coletiva dos trabalhadores na busca por alternativas econômicas ou manutenção de postos de trabalho. Esse artigo apresenta um contexto mais geral do cooperativismo, situando um processo que resultou do aumento do desemprego e da reestruturação produtiva, implicando restrições ao trabalho assalariado e conduzindo, entre outras soluções, a essas experiências de "fábricas recuperadas", que representavam soluções para os trabalhadores dispensados.

Dialogando com a situação discutida acima, o artigo "Sobre a diversidade de formatos e atores sociais no campo da economia solidária”, de autoria de Luiz Inácio Germany Gaiger, Marília Veríssimo Veronese e Adriane Vieira Ferrarini, trata dos vários formatos jurídicos da economia solidária, buscando não caracterizá-la, de início, como forma de organização do trabalho (emprego), mas apresentando uma análise mais ampla considerando-a como forma de organização das várias atividades econômicas - associação, cooperativa, grupo informal e outros. Ele demonstra como a diversidade cultural na constituição desses empreendimentos é bem maior do que costuma ser, considerado, predominantemente, em termos de cooperativismo urbano ou rural, a exemplo de um grupo quilombola, uma associação de pescadores artesanais, ou uma cooperativa urbana integrada à economia das grandes cidades, apresentando uma interessante discussão sobre a importância da dimensão cultural desses empreendimentos.

No artigo seguinte, Morte por exaustão no trabalho, de Cândida da Costa, focaliza-se o processo de trabalho desenvolvido no setor sucroalcooleiro no interior do Estado de São Paulo, caracterizado por intensa produtividade e competititvidade, resultante da inserção brasileira no agronegócio internacional. $\mathrm{O}$ artigo também focaliza o deslocamento interregional do trabalho migrante brasileiro, destacando a condição dos usineiros, de produção por metas, marcadas pela superexploração dos trabalhadores, o que se caracteriza por fatores como pagamento por produção, ausência de limites, jornada de trabalho de dez horas diárias e altas metas de produção, além de deficiência na intermediação e fiscalização das relações de trabalho. Essas questões são analisadas diante da quase inexistência de estudos que comprovem a relação entre as mortes e a exaustão por sobre-esforço no trabalho, mas argumentando-se que tal relação tem sido levantada por pesquisadores, pela Relatoria Nacional do Direito Humano ao Trabalho, pelo Ministério Público do Trabalho da $15^{a}$ Região de São Paulo e por vários meios de comunicação, o que levou ao desenvolvimento de pesquisa no período de 2004 a 2014, cujo ponto de partida foi constituído por entrevistas com trabalhadores diretamente nas frentes de trabalho nos canaviais, abranngendo denúncias sobre mortes, pelo Serviço da Pastoral do Migrante de Ribeirão Preto (Guariba) e outras instituições.

Por fim, o artigo Revisitando os efeitos de lugar: segregação e acesso ao mercado de trabalho em uma metrópole brasileira, de autoria de Ângela Maria de Carvalho Borges e Inaiá 
Maria Moreira de Carvalho, aborda aspectos relacionados à dinâmica mais ampla das cidades, considerando que são influenciadas negativamente pela distribuição dos estabelecimentos comerciais e de serviços e as oportunidades de emprego e de obtenção de renda, com vistas a focalizar a crescente distância espacial entre os locais de residência e os de trabalho, estudo e acesso aos diversos serviços por parte de grande maioria da população. Tendo como cenário a cidade de Salvador, as autoras discutem os obstáculos à integração produtiva, especialmente de grupos com atributos menos valorizados no mercado de trabalho, focalizando o perfil e a condição ocupacional dos trabalhadores de acordo com o seu local de residência, e observando que a vulnerabilidade desses contingentes tende a ser acentuada pelo "efeito território”, conceito apoiado em literatura da sociologia urbana.

De um ponto de vista metodológico, o conjunto de trabalhos pode ser caracterizado, de modo amplo, como estudos de caso, e, em alguns deles, garante-se a memória de momentos culminantes de certos processos que envol- vem o grande capital e grandes empregadores de força de trabalho, como os casos da Embraer da Petrobrás e de Programas de Emprego, ou ainda os casos das fábricas recuperadas, e do setor sucroalcooleiro. Outra característica que vale a pena destacar, em alguns dos trabalhos, é a coautoria de alguns pesquisadores mais reconhecidos com aqueles que ingressam na cena acadêmico-cientifica em tempos variados.

Recebido para publicação em 25 de janeiro de 2017 Aceito em 30 de janeiro de 2017

\section{REFERÊNCIAS}

BALTAR, Paulo. Emprego, políticas de emprego e política econômica do Brasil. Documento de Trabalho n.2. Escritório da Organização Internacional do Trabalho, $1^{\text {a }}$ edição, 2010.

BIHR, Alain. A Fragmentação do proletariado, In: $D a$ grande noite à alternativa, o movimento operário em crise. São Paulo: Boitempo, 1998.

IBGE. PNADhttp://www.ibge.gov.br/home/estatistica/ indicadores/trabalhoerendimento/pnad_continua/default_ novos_indicadores.shtm

OLIVEIRA, Francisco. Crítica à razão dualista - O ornitorrinco. Ed. Boitempo, 2003.

Iracema B Guimarães - Doutora em Sociologia pela Universidade de São Paulo/USP. Professora do Departamento de Sociologia da Universidade Federal da Bahia. Coordenadora do Programa de PósGraduação em Ciências Sociais (1994-1996 e 2005-2007). Integra o Núcleo de Estudos e Pesquisa em Humanidades/ CRH, desenvolvendo pesquisas na área de Sociologia do Trabalho, Estudos Urbanos, Estudos de Gênero, Família, Reprodução Social. Publicações mais recentes: Consequências de uma expansão periférica e seus efeitos sobre a população juvenil. 861X CEAS. Revista critica de humanidades, v. 235, p. 23-44, 2015; Periferias e territórios sob efeitos conjugados da precarização. Caderno CRH (UFBA. Impresso), v. 14, p. 87-102, 2011; Diferenciação dos arranjos domiciliares no espaço social urbano. Caderno CRH (UFBA), Salvador, v. 18, n.43, p. 1-18, 2005; Dinâmica urbana e contextos de periferização - tendências e cenários sociais locais. In: Gledhil; J. Hita, MG; Perelman, M. (org.) Disputas em Torno do Espaço Urbano, Edufba, 2017. 